\title{
Promoting entrepreneurship among informatics engineering students: insights from a case study
}

\author{
$\underline{\text { João M. Fernandes }^{1}}$, Paulo Afonso ${ }^{2}$, Victor Fonte ${ }^{3}$ Victor Alves $^{1}$, António N. Ribeiro ${ }^{3}$ \\ 1) Dep. Informática / Centro ALGORITMI \\ 2) Dep. Produção e Sistemas / Centro ALGORITMI \\ 3) Dep. Informática / HASLAB \\ Universidade do Minho, Braga, Portugal
}

\begin{abstract}
Universities seek to promote entrepreneurship through effective education approaches, which need to be in permanent evolution. Nevertheless, the literature in entrepreneurship education lacks empirical evidence. This article discusses relevant issues related to promoting entrepreneurship in the software field, based on the experience of a 15-ECTS course. This course seeks to instil in the students the recognition of the need to reconcile technical and business visions, organizational and commercial aspects, most of which never addressed previously. A series of semi-structured interviews made it possible to obtain relevant insights about the teaching-learning process underlying this course and its evolution over a 7-year period. Materials related with this course have been analysed, namely guidelines produced by the teachers and deliverables produced by the students. This article discusses the dimensions that were identified as fundamental for promoting entrepreneurship skills in the field of software, namely teamwork, project engagement, and contact with the market.
\end{abstract}

Keywords: entrepreneurship, project-based course, requirements engineering, software, business modelling.

\section{Introduction}

The society in general and companies in particular are dependent on software-based technological tools. The trend of this dependency is growing both in scope and in terms of sophistication. According to Anderson and Markides (2007), information and communication technologies (ICT) and the software industry made it possible to reduce transaction costs and led to new products and new businesses, many of them with a disruptive nature.

The bet in these strategic industries seeks to replicate successful models in other geographies, spawning new "Silicon Valleys". Perhaps like no other, the ICT industry is directly leveraged by the knowledge and the human resources of the universities. Additionally, the economic potential of this emerging industry is huge and is reflected in examples for all known as the GAFA giants (Google, Amazon, Facebook and Apple), but it is also present, in a less visible way, through software embedded in practically all the devices that we use in our daily lives.

In this context, there is a progressive tendency connected to the promotion of initiatives, such as degrees, courses, awards and competitions, to stimulate, among the population in general, and university students in particular, an entrepreneurial attitude. Entrepreneurship is related to the creation of something different and with (economic) value. Entrepreneurship is closely linked to the concept of change, i.e., entrepreneurs are agents of change and entrepreneurship is the phenomenon associated with the change process (OECD, 1998). Indeed, the entrepreneur devotes time and effort, assumes risks of various natures (financial, social and psychological) associated with such process of change and expects to receive the respective rewards (personal and economic).

The fields of software and ICT are especially attractive to be exploited in an entrepreneurial perspective (Szirmai et al., 2011), because of its intangible nature and the relative easiness of worldwide, large-scale distribution, and service deployment. Furthermore, stimulating an entrepreneurial attitude in students is valuable, due to several factors:

1. The society needs people with entrepreneurial spirit, because ultimately these are the ones that create profitable products, services, and jobs as well as companies and businesses. 
2. The software market is a high-tech market, characterised by high levels of technological uncertainty. The convergence between the industries of telecommunications, software and contents creates many new opportunities for software companies, providing the development of new types of products and services and new value propositions for the different customer segments. Thus, (software) companies need innovative, entrepreneurial and technologicallyskilled developers, because the software business relies heavily on the innovation that is incorporated in new products, the type of services that are provided, and the characteristics of the business model.

3. Most professionals - somewhere along a successful career - need to answer an inner calling to develop an independent and personal project so that they feel themselves accomplished, motivated and stimulated. Some (not many) of these professionals will try to succeed with their own business. The others will certainly strive to implement their projects, and induce innovation through the implementation of such projects in the organizations where they collaborate.

Thus, universities should design and implement effective educational and training strategies to turn their students into potential entrepreneurs and increase their chances of being successful in an environment of constant innovation and competitiveness. The existence of a synergy between research and education empowers research-oriented establishments to boost modern engineering skills and foster innovation attitudes including motivation for entrepreneurship, being this synergy the simplest relationship to be identified between both these university missions (Casar, 2000).

Indeed, according to Mishra et al. (2007), the quality of the software is a direct consequence of the quality of software engineering education. Education institutions are responsible for preparing professionals with the right set of competencies and skills to meet the expectations of the industry. These authors defined a set of dimensions to measure every course overall quality. The proposed analysis dimensions are interdisciplinary skills, practice experience, communication skills, skills on continuing education and professionalism. Thus, universities should allow their students to develop and consolidate knowledge and skills in fundamental tools that give them sustainable competitive advantages in a very demanding market. Indeed, the technological advances driven by the software industry enable companies to create and reinvent products and business models. There is a permanent change in the way electronic businesses are created and developed, mainly due to new technologies.

Therefore, the development of entrepreneurship in the field of software assumes an increasing and essential importance and should focus on the ability of students to acquire skills for developing new products and businesses that take advantage of their technical competencies and a good interconnection with the market. The early use of tools for conceptualising business models (Osterwalder and Pigneur, 2010) and methodologies for product development (Osterwalder and Pigneur, 2014; Ries, 2011; Blank, 2013) may be important in this context.

For Stewart and Zhao (2000), business models reflect how the company intends to obtain revenues and make a profit and how it is possible to keep that cash flow over time. This is the common understanding between informatics about "business models". However, the notion of business model should be understood from a much wider perspective. Indeed, it can be presented considering a set of several interconnected elements, e.g., the nine building blocks suggested by Osterwalder (2004), which turn possible several important functions that support the business. For instance, Chesbrough (2010) considers that a business model fulfils seven important functions. Furthermore, new and disruptive business models are challenging the status quo and such changes in management and business strategy can be translated into new markets, new products or new conceptions of the business model - for such business innovation or strategic innovation see (Anderson and Markides, 2006).

The specific domain of software development and related business models result in significant challenges that must be considered for the design and implementation of effective teaching models for entrepreneurship and entrepreneurial training. In fact, there is a need to successfully promote entrepreneurship in universities through effective education paradigms. These, in turn, need to be in permanent evolution.

This paper presents and discusses issues related to promoting entrepreneurship in the software field within a 15-ECTS (European Credit Transfer and Accumulation System) course, designated "informatics engineering project". The course aims to give a learning experience on 
ideation/innovation and subsequent product and business development. Product development is the set of activities starting with the perception of a market need and ending in the production and sale of a new product satisfying that need. Broadly speaking, it is a process that should follow a structured methodology, if a certain level of effectiveness and efficacy is envisaged. Nevertheless, even when this perception exists, it is hardly integrated with the company's culture and related processes. For example, according to Silva et al. (2009), in the Portuguese industrial environment, there is a weak perception of this methodology.

This paper aims to evaluate the development of entrepreneurship capabilities in a project-based course for informatics engineering students during a 7-year period. A series of semi-structured interviews made it possible to identify the relevant dimensions related to the teaching-learning process of the course over the studied period. Materials produced by teachers and students (e.g., guidelines materials for the course prepared by the teachers and outputs and deliverables produced by students) were also analysed.

\section{State of the Art}

Active learning is an educational approach that focuses the responsibility of learning on students. It basically engages students in two aspects: doing things and thinking about the things they are doing (Bonwell and Eison, 1991). All active learning approaches suggest that in order to learn, students must read, write, discuss, or be engaged in solving relatively-complex problems. More specifically, students must be involved in higher-order thinking tasks, like analysis, synthesis, and evaluation. Active learning encompasses many challenges, both for teachers and students, as discussed for example by Saalman (2009). Project-based learning (PBL), the educational approach followed by the course presented in this paper, is an active learning educational approach, in which students gain knowledge and skills by performing a set of tasks within a concrete project.

The promotion of entrepreneurship in engineering education, more specifically in software engineering is getting significant attention. In particular, it is evident that entrepreneurship requires active educational approaches, so that students learn new skills and reflect on what they have learnt and how they can benefit from and apply those skills. The experience reported by Järvi et al (2015) is a good example of such effort where technical competencies are combined with business and market issues. Particularly, it describes the use of the lean startup method in this context.

For instance, Rosca (2007) presents and discusses a requirements engineering course, at Monmouth University, covering the process, methods and tools specific to this area, together with the corresponding software quality issues. The paper describes the multidisciplinary, active, and collaborative approaches used in teaching requirements engineering.

Cagiltay (2007) describes the use of game-inspired exercises to address all the relevant topics of software engineering. The fact that the context goes around games provides an environment more appealing to students and therefore they tend to become more involved with the project. The thesis of the work is to validate if computer game-development courses improve the students' performance in software development projects. For that purpose several software engineering courses were selected and a study on the grades obtained was conducted to properly infer if there was any correlation. The study addresses both quantitative and qualitative data. Regarding the quantitative aspects, it shows that on average students that enrolled in the game-development course had slightly higher grades than the students that did not. An independent sample t-test was conducted and determined that the difference between the distinct groups was not significant. In what concerns qualitative data, the students conveyed the idea that the challenge that game development presented was responsible for evolving in autonomous work, mostly by using independent learning, and to acquire problem-solving abilities and learning by doing.

Also Johannisson et al. (1998) present insights on how providing students the opportunity to explore their entrepreneurial skills has an impact on students' action capability towards entrepreneurship. In particular, these authors demonstrate that students participating in educational programmes with focus on entrepreneurship, namely innovation engineering students, show a higher action capability than students joining traditional/conventional programmes. They also show that students enrolled in entrepreneurial programmes with an engineering orientation show a higher action capability than those in parallel business programmes. 
Indeed, the enhancement of personal skills, non-technical aspects of the development, implementation and use of technology, teamwork, project management skills and entrepreneurship are of increasing concern for engineers and therefore for engineering education. Even, personal specific psychological characteristics should be considered (Capretz and Ahmed, 2010). This led to the introduction of courses with this concern in mind. For example, in 1996, at the Delft University of Technology introduced a subject on sustainable entrepreneurship and technology in the course programmes of Chemical Engineering and Materials Sciences Engineering (Bonnet et al., 2006). This subject combines lectures, project work in which a business plan is written, sustainability and presentation training. The authors conclude that one can successfully mix entrepreneurship, sustainability and project education in a subject for undergraduate engineering students. They also discuss on how to integrate sustainability and entrepreneurship in terms of the triple P (People, Profit, Planet) and how to include it in the major elements of a business plan: (1) business idea, mission and strategy; (2) context, stakeholder and market analysis; (3) marketing; (4) production; (5) organisation and management; (6) finance and reporting.

On the topic of entrepreneurship education, Papayannakis et al. (2006) state that "While entrepreneurship has emerged as an important mechanism for the generation of social returns in terms of economic growth and job creation, entrepreneurship education is still something new in Europe and the debate about the need and the way of introduction of specific entrepreneurship courses in higher education is on going". Papayannakis et al. (2008) address the introduction of entrepreneurship education in engineering curricula. They present the experience at the National Technical University in Greece and discuss the need for interdisciplinary approaches in engineering curricula. These authors argue that the introduction of entrepreneurship education in university curricula should be part of a more general discussion related to educational priorities and of a strategy of university curricula, so that engineers can be provided with entrepreneurial and management skills.

In university engineering degrees curricula, there is usually a reduced integration of interdisciplinary knowledge that allows students to have an understanding of what are the main issues and challenges related to product development integrated with entrepreneurship. Silva et al. (2009) present an integrative approach to bridge the gap between industry and university by discussing a course on product development and entrepreneurship, at a graduate level. The course puts emphasis on innovation and creative thinking during concept development, through the introduction of a structured method to promote it. By addressing intellectual property rights, the students are motivated to innovative thinking. Thus, teaching product development integrated in an entrepreneurship framework promotes students' skills related to initiating a new business and to executing the idea-to-product viability evaluation in a business perspective (Ries, 2011; Blank, 2013).

\section{Research Methodology}

In this research project, the case study method and a qualitative approach have been followed. In the qualitative method, the researcher develops conceptions based on facts and on the perceptions of the involved persons to understand the phenomenon (Saunders et al, 2009). According to Yin (2003), the case study is an empirical research, which focuses on the context of a contemporary phenomenon, being especially developed when the boundaries between the phenomenon and the context are not clear. Yin adds that the case study can be characterised by a search design related to one or multiple cases, and these can, in turn, contain themselves one or several units of analysis within the context to which they belong. In this context, the research strategy can be exploratory, descriptive or explanatory (Yin, 2003). In the first approach, the research intends to determine the truth or falsity of a given theory and how it can be changed and extended. The descriptive strategy focuses primarily on the description of a certain situation. Finally, an explanatory strategy is suitable for investigations that aim to find relationships between variables in order to explain relatively complex phenomena. Yin (2003) points out that we can use these different research strategies, recognizing that they have associated advantages and disadvantages which vary according to the type of research question, the control the researcher has over the course of events, and the type of focus on contemporary phenomena.

Data collection is a central task in an academic research project, particularly if it has a qualitative nature. In such cases, it is time consuming due to the need to obtain and analyse a huge amount of qualitative information, typically presented in terms of texts which were transcribed from video or audio records obtained through interviews, direct observation or participatory approaches. Qualitative 
data refers to all non-numeric or not quantified data that can be collected through (Saunders et al., 2009:480): (a) documents, (b) file records, (c) surveys (d) participant observation, and (e) physical artefacts.

According to Bogdan and Biklen (1994), the interview is used by the researcher to collect descriptive data on the subject's own language and to develop intuitively an idea on how the subjects interpret some aspects of the world. For Patton (1990), there are three types of interviews: unstructured (open) interview, semi-structured, and structured (closed). The interview is a data collection technique, especially important when conducting a qualitative research. It requires individuals properly prepared to conduct it and with the ability to diversify the questions with the objective of obtaining diverse responses on the topics under consideration. Another feature of an interview is the direct interaction with the respondent, providing a greater contact with him/her. For the interview not becoming monotonous and for the deepening of the topics that the investigator intends to address, the interviewer must actively participate in the process, thus avoiding a dispersion of the theme. An interview can be: (a) face-to-face, (b) phone-based, or (c) in a group.

In the case of this study, the data collection was made using semi-structured interviews to students and former students, informal contacts with teachers, and through the analysis of materials produced by the teachers (documents with course orientation and guidelines) and by the students (outputs and deliverables produced in the context of the course. Furthermore, one of the researchers participated in assessment meetings and presentations in the last 3 editions of the course - in these cases they were just taken hand-notes.

All interviews were face-to-face and recorded in audio, with the due consent and authorization of the interviewees. The choice for conducting interviews had in mind the direct contact with the sources, allowing a detailed and thorough knowledge of the reality in question and proving to be well suited to the goals of the study. Furthermore, semi-structured interviews permit to obtain rich empirical data and may offer insights not expected or anticipated.

The interviews should be based on a set of questions previously prepared and which serves to guide them. One does not require a specific order to ask the questions. In fact, the interviewer can adapt the interview to the interviewee and explore the issues in a flexible way (Saunders et al., 2009). In this research project, we have used the questions presented in Table 1.

Table 1. Script for the interviews

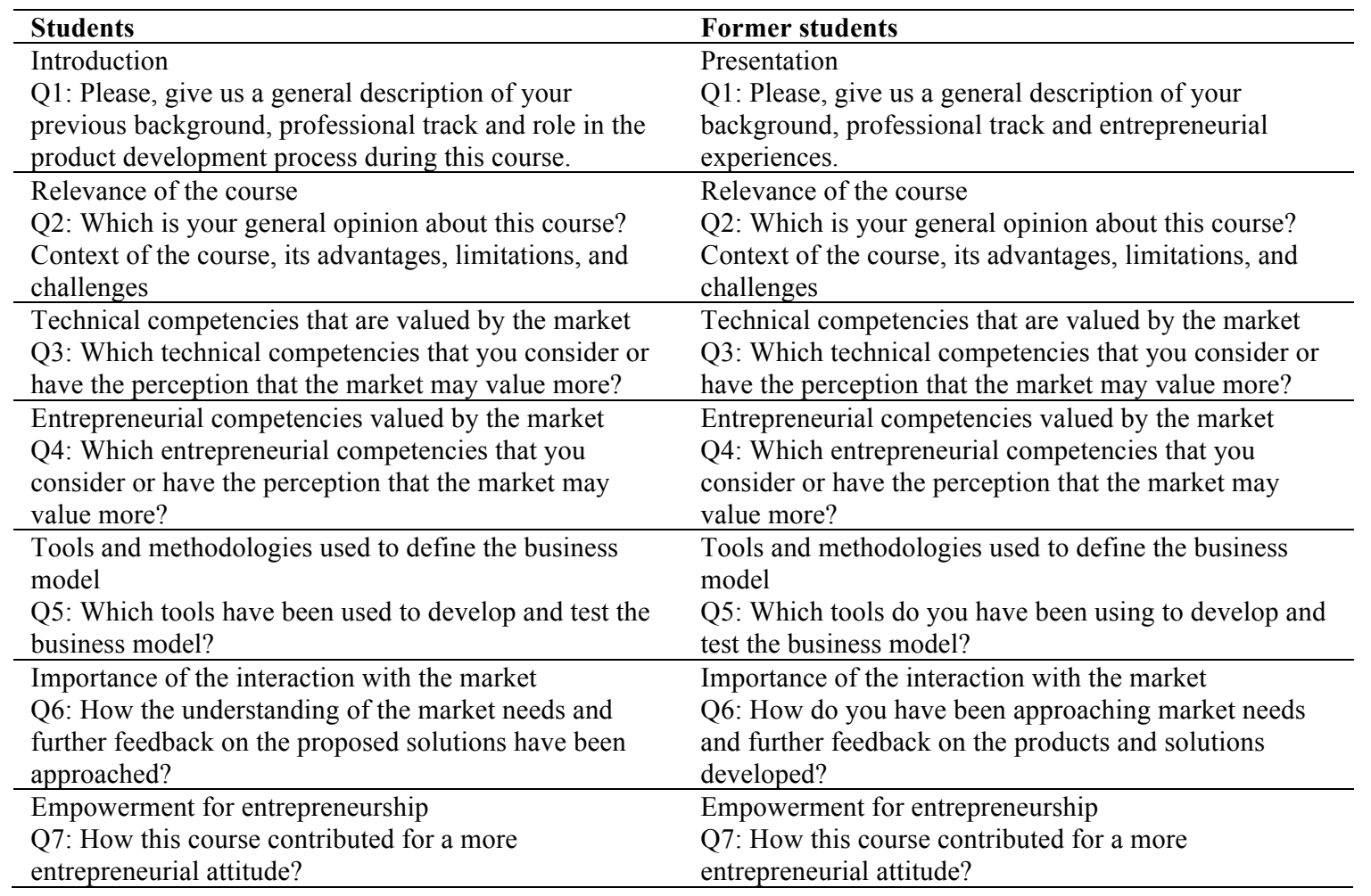


Eight groups of students and four former students were interviewed. Students were interviewed in groups and former students individually. The groups of students were composed of 4 to 8 people, including always the team leader. The interviews had the average duration of 20 minutes (for the groups of students) and 30 minutes (for former students). During the interviews they were also taken hand-notes.

One researcher conducted the interviews and, in some cases, a second researcher took hand-notes. All interviews were recorded, transcribed, and later analysed to create reports that were successively reduced and further discussed in order to produce a final report for each interview. The transcription of each the-interviews took between 2 and 4 hours, so in total around 40 hours were spent in this task.

The interviews and respective hand-notes transcripts were revised several times and permitted to produce a report of several pages of text. Then, the empirical data was broken down, examined and categorized. A process of open coding has been used to interpret the data. The main findings were discussed and reinterpreted by the researchers. Tables and matrices have been used to reduce the data and highlight patterns and findings. There was no usage of any qualitative data analysis software.

Furthermore, the data collected from the interviews were complemented with materials related with the course, particularly, the document that contains the guidelines prepared by the teachers and presented to the students in the beginning of each academic year. This 11-page document reflects the evolution of the course. These guidelines consider also the deliverables produced by the students and the results obtained during this period of seven years.

The data of the interviews and main findings were finally reinterpreted considering these materials related with the course. The most relevant findings are presented and discussed in Section 5.

\section{Case Study}

The course "informatics engineering project" was launched in the academic year of 2009/10 and it is part of the last year of the Informatics Engineering masters' degree, promoted by the School of Engineering at the University of Minho. It is a 15-ECTS course, corresponding to a total effort of 420 hours for each student (1 ECTS is equivalent to 28 hours). Assuming an 18-week time window, each student is expected to dedicate to the course around 23 hours every week, eight of them on site at the university facilities.

It seeks to instil in students the need to reconcile the technical vision, which they all master, with a focus in business and entrepreneurship that most of them never addressed in educational contexts. This course aims to enable students to acquire a core set of competencies related to a team-driven development of a software product, and the analysis of the business potential of products.

During the course, students develop a software product and (2) analyse the business potential of that product. Students are organised in relatively large teams ( 8 or 9 students) and are expected to carry out the project within a limited timeframe, i.e., around four months (from late September to early February). The evaluation is made during the execution of the project based on the deliverables and evidences that are collectively produced.

As a result, students formally acquire a set of technical competencies and soft skills that in most cases were not duly explored in their previous academic experience and that are extremely valuable for the market (Markes, 2006). On one hand, these competencies ask for technical knowledge such as engineering requirements, designing and testing. On the other hand, the set of soft skills includes leadership, team organisation, communication and presentation, business modelling, and entrepreneurship.

In particular, students apply and develop many competencies and skills associated with the software engineering field, but that can also be framed under the entrepreneur umbrella. Table 2 presents these competencies and skills, which are very broad in scope. It not only includes technical competencies, as expected for engineering students, but also several soft skills.

In addition to the goal of constituting a balanced and motivated group, it is important to adopt a methodology for effective work. Teachers recommend the use of the development cycle 'Lean Startup' (Ries, 2011) which is aligned with agile and scrum paradigms in software development. The goal is to perform minor cycles of development, adopting a combination of testing of hypotheses of 
product value, through the use of early versions of the product. In this way, validation cycles are performed until a valid value proposition is obtained. This validation process should be performed based on the feedback obtained from (potential) customers.

Table 2. Technical competencies and soft skills developed by the students during the course

\begin{tabular}{ll}
\hline Competencies / Skills & Description \\
\hline Interact & Interaction with the client; Communication of design decisions to clients and end users. \\
\hline Plan & $\begin{array}{l}\text { Planning and follow-up of a software development project; Review of the plan during } \\
\text { the execution of the project; Assessment of the initial expectations and estimations. }\end{array}$ \\
\hline Work in team & $\begin{array}{l}\text { Coordination of a team, its meetings and the internal communication; Use of } \\
\text { cooperative work tools for developing software, such as traceability tools, software } \\
\text { repositories, project management tools, and version control tools. }\end{array}$ \\
\hline Design and develop & $\begin{array}{l}\text { Realisation of a development project; Requirements elicitation and prioritisation; } \\
\text { Design; Implementation; Documentation; Test and validation of the system. }\end{array}$ \\
\hline Present & $\begin{array}{l}\text { Presentation of the project, product, plans and documents to stakeholders and the public } \\
\text { in general; Writing documentation that is readable and useful. }\end{array}$ \\
\hline Produce & Creation of a new product. \\
\hline Validate & $\begin{array}{l}\text { Comparison of the product with the competitors; Creation of a business plan for the } \\
\text { product. }\end{array}$ \\
\hline
\end{tabular}

In order to bring external contributions, the teachers promote regular visits (in a weekly basis) of experts in the software business field. These visits allow teams not only to obtain technical feedback about their projects but also advice regarding their product features, or even related to their business model. In the same sense, one has organised seminars on topics that recurrently have been indicated as indispensable and useful: (1) development of business plans for software products, (2) project management, and (3) agile software development.

The interaction with the outside world culminates and has its defining moment on the final pitch. In the last editions, this pitch was held at the facilities of StartupBraga (a local agency that supports technological startups) and the session was open to the general public (including media). Two of the ideas developed in the last two editions of the course were incubated.

The course follows the strategy proposed by Perkins (2010), in the book "Making Learning Whole", which argues that any subject at any level of education can be achieved more effectively if the students are faced with a holistic perspective of the problems, rather than isolated parts. Perkins (2010) describes the resulting benefits for students from learning in the context of creating a real world artefact, making use of existing market tools and best practices.

The operationalization of the course is based on a set of steps and makes some assumptions that are explained below.

1. Ideation and Idea Selection: Preferably, the ideas should be proposed by students; thus, they will be much more motivated to develop them. It is possible to consider ideas from a third party, but this is a situation to avoid.

2. Team Composition: The number of students in each team varies depending on the number of students enrolled, but should be between 8 and 9. It is suggested the choice of students with different technical backgrounds in order to have people in the team with different and complementary competencies and skills.

3. Course Phases: It is divided into two phases, the first one where the focus is identifying and developing the business idea and the second one focused on product development.

4. Seminars: This course requires various skills that, in most cases, students did not address in their academic experience. Thus, there is an opportunity to exploit those skills. But, it is not possible for the teaching staff to address all such topics. Thus, seminars are organized on topics that have been repeatedly shown to be necessary and that teams understand as useful.

5. Weekly Meetings: The teams are mandatorily together one day a week (by setting up a full schedule of eight hours, from $9 \mathrm{~h}$ to $18 \mathrm{~h}$ ). That period is also used for the team to meet with the teachers and invited tutors.

6. Technologies and methodologies: No technology or software development process is imposed, neither one forces the use of a specific approach to build the related business model. The teams can choose what they prefer or evaluate as adequate.

7. Contact with the Market: The teachers promote regular visits of experts in the software business area. 
8. Pitches: Three pitches are made throughout the project development ( 3 to 5 minutes presentations). The first pitch (initial) takes place in an early design phase (in October), when the idea is not fully defined yet, thus seeking to obtain some feedback on the feasibility of the idea and how to continue with the project. The second pitch (academic) takes place when the project is near the end (January) and it permits to evaluate the product and the business model proposed by each team. The third pitch (business) takes place when the project is over (February) and aims to present the product and its business model to a panel of experts from the software industry.

9. Assessment: At the beginning of the semester, two dates for the deliveries related to the projects are established. In the first delivery, which occurs in early November, each team shall provide a requirements document and a business plan (both in an intermediate version). The second delivery (in early February) should include the following elements: product vision; document requirements; project plan; project state of the document; installation documentation (if applicable); manual (or alternatively videos with explanations or help menus); software product functioning; and business plan. The grade of each team is calculated based on the following four elements: material of the first delivery $(20 \%)$, contacts outside the university (20\%), material of the second delivery (50\%), and the academic pitch (10\%).

At the end of the course, each team must deliver a software system working properly, being not acceptable just a plan or a simple vision of the system or a prototype. The teams should also submit the source code, the tests performed, and related documentation. The product should be developed in a professional manner and function as expected with no obvious defects. The product shall be validated from not only a user point of view, but also from a technical one in order to check how it is built and organised.

\section{Results and Discussion}

According to the perceptions of the teachers involved, the opinions of the students, and the contributions of former students, the course has evolved considerable in the last seven years. A first description of the course is available in (Fernandes et al., 2012), which reports results after delivering the course in two different academic years. A course with this type of characteristics has to comply with the expectations of the students, but it cannot stray away from the guiding pillars that the teachers want to ensure. Additionally, the contributions of external elements, such as partner companies, entrepreneurs, members of the evaluation panels, and former students, must also be considered. In this paper, the opinions and contributions of former students, who launched software products or businesses after attending the course, are discussed.

Table 3 presents in a simplified form the evolution of the course in terms of the number of products developed and the number of students enrolled, on one hand, and of teachers and external elements, on the other.

Table 3. Evolution of the course

\begin{tabular}{lcccl}
\hline year & $\begin{array}{c}\text { \# developed } \\
\text { products }\end{array}$ & $\begin{array}{c}\text { \# enrolled } \\
\text { students }\end{array}$ & $\begin{array}{c}\text { \# involved } \\
\text { teachers }\end{array}$ & panel members and guests \\
\hline 2009 & 2 & 65 & 5 & - \\
2010 & 4 & 79 & 5 & - \\
2011 & 5 & 61 & 5 & 15 persons, 4 institutions, 10 companies \\
2012 & 5 & 95 & 4 & 7 persons, 1 institution, 6 companies \\
2013 & 5 & 100 & 3 & 5 persons, 5 companies \\
2014 & 8 & 73 & 5 & 19 persons, 4 institutions, 12 companies \\
2015 & 8 & 66 & 4 & 23 persons, 4 institutions, 17 companies \\
\hline
\end{tabular}

The number of teachers remained relatively stable, usually five, with two of them being associated to the course since its first edition. Starting on the third edition of the course a number of external guests, were invited to participate in the course as technical and business consultants. In the 2012 and 2013 
editions, there was a decrease in this participation; however, in the last years, an effort was made to reinforce the participation of external guests.

All teachers who have been collaborating in this course highlighted the increasing and remarkable noteworthy progress in the technical complexity and sophistication of the solutions and products that have been developed by the teams (observed by the quality of coding, maturity of the beta versions of the products presented, etc.). The teachers consider that the quality of the value propositions of these products has also improved considerably, which results from the increasing effort dedicated by the teams to this issue. For example, in the last two editions, an increasing number of teams have substantially changed or improved their initial product idea, since the value propositions were not considered sufficiently satisfactory. This evidence improvement is also a consequence of the contacts made with different business stakeholders, which promoted a better adjustment between the product and the market.

Table 4 presents the list of products developed within the course.

Table 4. Products developed during the seven editions of the course

\begin{tabular}{|c|c|c|c|c|}
\hline Year & Product & Description & $\begin{array}{c}\text { Technical } \\
\text { quality }\end{array}$ & $\begin{array}{c}\text { Market } \\
\text { orientation }\end{array}$ \\
\hline \multirow[t]{2}{*}{2009} & Full Sense & Protection against theft of computer equipment & 1 & 1 \\
\hline & wenove & Management of organizational processes & 1 & 1 \\
\hline \multirow[t]{4}{*}{2010} & EVTL & Virtual magnetic tape library & 3 & 2 \\
\hline & Flexes & Centralization of insurance policies & 2 & 1 \\
\hline & iCatcher & Management of information displays & 3 & 2 \\
\hline & Simon & Management of student associations & 2 & 3 \\
\hline \multirow[t]{5}{*}{2011} & egend.me & Management of professional agendas & 2 & 2 \\
\hline & FaceRecognition & Access control based on facial recognition & 2 & 1 \\
\hline & HoneyPot & Protection for computer networks & 2 & 2 \\
\hline & JobMarket & Management of curricula vitae and job offers & 2 & 1 \\
\hline & SkillWorld & Acquiring skills in Facebook & 2 & 2 \\
\hline \multirow[t]{5}{*}{2012} & MobileCity & Tourist guides to cities & 2 & 2 \\
\hline & NeuroPump & Neuropsychology queries management & 3 & 2 \\
\hline & Plazr & Online store for sports products & 1 & 1 \\
\hline & Raso & Human resource management & 2 & 2 \\
\hline & Siga! & Management of small tasks & 2 & 2 \\
\hline \multirow[t]{5}{*}{2013} & AgroSocial & e-Market for exchange and sale of agricultural products & 2 & 2 \\
\hline & CityRoots & Tourist guides to cities & 2 & 1 \\
\hline & CloudStar & Search in the cloud & 2 & 1 \\
\hline & Hostels4all & Management of hostels & 2 & 3 \\
\hline & ReadingOwls & Social network for reading clubs & 3 & 2 \\
\hline \multirow[t]{8}{*}{2014} & CLAP & Information for university campuses & 2 & 1 \\
\hline & CloudProphet & Integration of cloud storage services & 3 & 2 \\
\hline & Duster & Home cleaning services & 2 & 2 \\
\hline & Nutrium & Management of nutrition plans & 3 & 3 \\
\hline & Parkr & Information about car parks & 2 & 1 \\
\hline & Reconfigurable & Operational management of project teams & 3 & 1 \\
\hline & SOL & Parental control for mobile phones use & 2 & 2 \\
\hline & yWallet & Parental control for children pocket money & 3 & 1 \\
\hline \multirow[t]{8}{*}{2015} & Guestool & Management of guests to parties/events in night clubs & 3 & 3 \\
\hline & MedQI & Management of patient appointments in a clinic & 3 & 2 \\
\hline & Physier & Management of physiotherapy sessions & 2 & 2 \\
\hline & Rentind & Marketplace for renting industrial equipments & 1 & 1 \\
\hline & SEBIS & Management of sports events & 2 & 3 \\
\hline & SMYC & Social network for touristic guides & 2 & 2 \\
\hline & Sportgest & Management of futsal trainings and matches & 2 & 1 \\
\hline & WePlim! & Management of ideation/brainstorming sessions & 2 & 1 \\
\hline
\end{tabular}

3: High, 2: Medium, 1: Low

As Table 4 shows, the number of application domains addressed by the students is vast (e.g., tourism, agriculture, commerce, education, insurance, sports, healthcare, services, etc.). In the majority of the cases, students tend to opt for solutions that are relatively straightforward in technological terms. This option is somehow surprising, since it implies that the product should be strongly justified in terms of market opportunity, which asks for other skills than those typical found in informatics students. Contrarily, in the cases where there were important technological challenges (e.g., HoneyPot, 
CloudStar, CloudProphet, yWallet), it was acceptable that the teams focused their attention to those issues rather than to market and business ones.

The analysis of the data collected resulted in interesting findings that deserve our attention. Indeed, the various dimensions presented in the following sections are important lessons and can be used for planning and implementing educational courses with similar aims. The experience gained in the various editions of the course provides confidence with respect to various assumptions made in its functioning. On the other hand, there are some less obvious, but critical, dimensions that are important to highlight.

\subsection{Teachers' perceptions about the course}

The analysis that teachers did during the operation of the course, its limitations, positive aspects and challenges were materialised into a set of changes made over the years. The most relevant changes made during the seven editions of the course are the following:

1. The effort in reducing the number of students in each team (initially 30 students per team and currently about 8), which implied increasing the number of projects;

2. The preference given to projects proposed by the students, instead of external proposals;

3. The need for students to interact with business experts throughout the project, as a way to enable them to gain awareness of the necessity to constantly adapt the business idea until a value proposition with market potential is found.

Teachers consider relevant to assess the technological risk (i.e., how difficult it is to implement the project in the available time) of each idea and the risk of the respective business model, in order to manage and to better understand the effort and the results associated with each project. A project with little technological risk and with a classic business model implies that the team must explore more profoundly other aspects (e.g., sound user experience, solid market validation, methodical treatment of non-functional requirements, detailed financial analysis). On the other hand, a project with high technological risks or involving a disruptive business model may require a greater focus of the team in those aspects, which may justify a lower investment in others.

Issues related to the composition of the teams are important. Thus, they are addressed in the guidelines provided to the students As indieated in the course guidelines:

\section{A balanced team is a critical factor for the success of the projects. It is important to have a leader who knows how to manage the team.}

Usually the leader is the proponent of the project idea and in that role he/she has the right to accept (or not) in his/her team other students who wish to participate in the project. Every student has the right to remain in one of the teams. When it is not possible to reconcile these two conditions, it is up to the teachers the last decision on the composition of the teams.

Given the significant number of students who attend the course that also have an ongoing professional activity (partial or almost fulltime), their involvement in the project should be encouraged, because they can bring valuable experience. Thus, the teachers suggest teams to include students with different profiles.

This diversity is beneficial in the context of the two phases of the course: in the first phase, to potentiate differences in the creative process (i.e., ideation), which are beneficial for the development of a more robust business model; in the second one, to reinforce the team's technical know-how by creating a heterogeneous group of students with diverse software development competencies.

The course presented by Rosca (2007) includes many similar aspects to this course and also aims to "produce" software engineers with strong teamwork and communication skills, capable of working in multidisciplinary teams. Team composition and team dynamics are very important in this context.

It is also the assessment of the teachers that, since some projects demonstrate a real business potential, there are several ways to support the creation of technology-based companies for the commercial exploitation of the developed products. This is accomplished using the extensive network of contacts with businesses, incubators and other platforms that promote and support technology-based entrepreneurs in the region. 
The teachers highlighted that the interaction with the market to validate the product is typically done only at the end of the project, when there was already an alpha release. The students corroborated this fact. Indeed, in a given team, students ended up confessing they used the business model canvas only in the last two weeks.

\subsection{Students' perceptions about the course}

Students consider this course as notoriously different from the others in the degree, being clearly an experience that will remain in their memoirs. This is an important aspect, because it attaches to the course a huge potential to pass an important message to students.

This course is completely different from the previous ones, since the addressed topics are quite different. In the past, we programmed just to show that we were technically skilled. In this course, we need to develop a product but also to make it viable.

(Students Interview 1)

When compared with other project courses, this course was a huge step forward. The dimension of the project raised the bar.

(Students Interview 7)

Some of the students consider that the course has "raised the level", although others have not fully understood its goals. Most students appreciate the fact that the course enables them to work on their own projects and that it is required to completely develop the project (i.e., to construct a software product with potential to be launched into the market). Many students find some significant differences with respect to other courses whose outcomes have typically a more academic nature and as such do not have a strong relationship with market reality. In this course, however, students need to prepare a final presentation to a panel of - typically - non-academic external experts. Students have not mentioned only positive aspects associated with the course. Most of them consider that it requires too much time and involves a lot of work and suggest the need to change some aspects, namely the interaction with the external experts and the visitors, the presentations, and the interaction with the market. This last point deserves special attention and is explained in more detail below.

At the level of the skills associated with the course, students have valued the teamwork, the allocation of tasks and sub-tasks amongst the team members, project management, and the role of leadership. Indeed, in these courses, students are pushed to explore and to develop their entrepreneurial skills (Johannisson et al., 1998). Furthermore, Monaghan et al. (2015) also state that the teaching staff should give special attention to team personality, team norms, and social identification. It is possible to achieve a higher level of performance in the project if each student identifies himself undoubtedly as member of the project team as opposed to being an independent contributor to the project.

Furthermore, the awareness of the importance of the market in the development of the product is crucially relevant. It is essential to have a strong interaction with the market during the product development process, so that the needs of the end users are considered. Nevertheless, students recognise that this is a completely new concern to them in a university course. This is in line with what is reported by Papayannakis et al. (2008) and Bonnet et al. (2006) who refer that project teams should balance product development with the knowledge of who will sell it, where, to whom and at what price.

In fact, the opportunity to directly contact with the market, to get feedback from potential customers, and to be supported by entrepreneurs and business experts were highly valued by the students. According to students, the visitors helped the teams to improve their ability to explain the product and foster the discussion of diverse opinions on a number of different subjects. In some cases, it was recognised that the visitors even influence the projects. At the bottom line, the feedback received from the visitors resulted in new features and changes in the product and also in its business model.

Undoubtedly, the visits and the contact with the market were important and helped to define the product. The product has today features that were not considered at the beginning.

(Students Interview 3) 
Our idea is rather different when compared with what was initially planned. [...] We implemented things that the persons asked for.

(Students Interview 2)

However, in some cases in which the team tried to respond and consider all the suggestions made by the visitors, this permanent validation of the product and the constant recommendations entails some risks and difficulties that must be mitigated.

We tried to please all the visitors. [...] It is positive to have all these visitors, but often they limit us a bit, since they have different opinions that forced us to change things almost every week.

(Students Interview 3)

In fact, teams should have the ability to receive, digest, select and raise the different and even incompatible contributions. In this context, a good strategy implies the understanding that not all should be incorporated in the product, creating the need for the existence of a wishlist of functionalities to be assessed later on the product lifecycle. This is in line with the lean startup approach proposed by Ries (2011).

Taking into account that the visits and the support received every week were provided primarily by entrepreneurs in the software field, students highlighted the fact that it is also important to consider visits from potential customers, end users and consumers, and to reinforce the contact with the market. The contributions of the market should also influence the product in this phase of the project. Steve Blank's customer development method is a good framework for this process (Blank, 2013).

The component of the business model is the one that students feel they need to be better supported. Most of them suggest that attending some extra seminars on business planning and modelling would have been very useful. In addition to the difficulty in defining the business model, students felt that they invested a lot of time and effort in its preparation due to lack of experience and support. For some students, it was not noticeable at the beginning of the course that there was a market and business component so strong. Thus, some teams tend to be essentially focused on the technology and the product (i.e., to have it ready by the deadline), somehow neglecting business aspects. In the analysed cases, this is a very common problem.

Our focus was to have a working product at the end. We didn't focus on the business part.

(Students Interview 5)

We have developed the product based on our own user view.

(Students Interview 8)

It is important to highlight the existence of a kind of trade-off to be managed, i.e., business and market analysis versus technical and technological issues, because the first one is very time consuming and it is not an easy task for people with an engineering background. Nevertheless a good balance of these two different aspects appears to be a key factor for the success.

In this context, two generic approaches appear to emerge. These strategies may be developed in cases where the quality level of these aspects is not satisfactory. On one hand, if the team presents limitations, one can enhance and strengthen leadership, improve conditions for the formation of the team, empower the team with new knowledge, investing in the development of project management skills, etc. On the other, if the business idea does not support a robust value proposition, one can explore further the idea, consider additional contributions from the market, invest in business seminars, redefine or refocus the idea, and change the focus or promote a different idea (pivot in the language of the Lean Startup). Indeed, pivoting is an important movement in new product development in the lean startup proposed by Ries (2011).

The interviews with the students ended by questioning them about their future. Most of them do not seem to be interested to embark on an entrepreneurial career. Most of them, but instead prefer to start their career working as employees of someone else. The overwhelming majority wants to gain experience in a company. Experience and knowledge in solid and innovative firms are particularly important even more than higher salaries. Indeed, we may conclude that most of the students that want to be employed in an innovative company do not seek to have a high income. In fact, such companies 
tend to highlight the non-financial advantages such as the working atmosphere, flexibility of working hours, multifaceted experiences, among others.

Firstly, I want to work in a company to gain experience. It is important to understand how the market works.

(Students Interview 1)

I want to have a professional experience. Afterwards, why not trying to create my own company?

(Students Interview 7)

Despite the fact that all the students consider themselves ambitious, they are not sure if they will create their own business in the future. Interestingly, the leaders of the teams, which generally were the promoters of the ideas, show willingness to create a business, even before entering in a wellestablished company. This was clear from the interviews with students.

Furthermore, some students have verbalised the intention of continuing the product on which they were working during the course. From the last editions, two ideas (Nutrium and CloudProphet) are being further explored as a real business. In particular, Nutrium (https://nutrium.io/en) has already captured the attention of investors and they are operating in the market.

\subsection{Former students' perception about the course}

Former students corroborated the opinions of the teachers and the current students, but have an interpretation of the course that enables a link between the past, the present and the future of the course to be made. The main lessons drawn from these interviews are next discussed.

A very important finding is that the projects that are developed in the course tend to be kept in standby, either waiting for an opportunity or simply because it was proven that they are financially unfeasible. According with the former students, this situation may hopefully change in the future if the business issues of the projects are weighted in and considered early on in the process.

Our idea developed in the course is in standby. We want to pick it again in the future, but for now we are developing a new idea.

(Former Students Interview 3)

After the course, we maintained interest in developing the project idea, but we arrived to the conclusion that it was not feasible due to issues related to the business plan. We jumped to a new idea, but with the same persons.

(Former Students Interview 5)

Former students, corroborated by the teachers, stated that often teams kept working after the end of the course, embracing new projects rather than pursuing the ones they were originally working on. In other cases, sponsors or business partners may invest on the teams and not really on the project.

This course puts the persons to work in teams and creates relations with the colleagues that one may wish to repeat in the future in more ambitious projects. [...] At the end of the course, a member of the panel approached us to start a new business idea.

(Former Students Interview 1)

All former students interviewed were selected because they are currently developing or have already launched software products on the market and they all continue to work with some elements of the original team. These entrepreneurs highlighted that the opportunity to continue the development of the business ideas in order to launch products on the market requires certain conditions to be fulfilled. As was mentioned by the first former student interviewed, it is necessary to establish conditions for entrepreneurship, such as an appropriate team, some kind of financial safety to move forward with the project. Being an entrepreneur entails many challenges and difficulties, is very demanding, and the results are not immediately apparent; according with him, "success is not achieved overnight."

Students tend to think that they need fast and immediate solutions with a very short time-to-market in order to take advantage of the window of opportunity, but the process of translating an idea into a product and a business is far more time consuming and is composed of several steps. Former students recognized it very clearly. 
The $4^{\text {th }}$ former student interviewed is a paradigmatic case of this process. The idea he worked on during the course did not get market traction, regardless of its clear technical merits (FaceRecognition). Despite his plans for starting a company after graduation with a number of his colleagues, he first started by working in a company for 1.5 years. This gave him the time he needed to mature a better business idea. Later on, he benefited from an entrepreneurship scholarship that financed the work of developing the idea for 12 months, in order to achieve a viable product (Ribeiro et al, 2014). After this period, the team of promoters got funding to support the company at that early stage allowing them to be now looking for new funding to continue the product development, envisaging a more robust and sophisticated outcome. In this period he developed and improved the product's value proposition, built an early stage prototype, and began to validate the product alongside with a growing group of users (orthopaedists). The team is currently collaborating with a renowned Portuguese medical doctor that works as a product evangelist and business angel.

In this case, it was also very interesting to note the deep understanding this former student already holds regarding the strategy and tools for business design. That certainly helped in elaborating the strategy on how to promote the product to the market, as it is highlighted by Osterwalder and Pigneur (2010).

There was a strategy initially defined with great detail; there was a business model that we would like to follow, which is based in selling our solution to the orthopaedic industry. We want to have a user base to subsequently grow gradually in the value pyramid.

(Former Students Interview 4)

Additionally, this former student also mentioned that the entrepreneurial training in universities tend to have a particular focus on empowering people rather than on developing ideas or products. However, the continuous evolution that this course has witnessed is promoting both aspects.

Another interviewee mentioned exactly the same point, i.e., the importance of defining a successful market penetration strategy: "how to make the first customers [...] make us known" (The $4^{\text {th }}$ former student interviewed). Indeed, the market entry strategy is one key element for the success of these kind of projects complementing a good business model designing (Osterwalder and Pigneur, 2014). Generically, one can approach the market for the first time with a new What, a new Who or a new How (Anderson and Markides, 2007).

Furthermore, former students highlighted that the course may evolve into more flexible formats depending on the dynamics of the groups and the characteristics of the students themselves, particularly of those that also have a professional activity outside the academy. These students-due to their maturity - would be able to significantly contribute to the evolution of this course, both on its technical and its business side. Nevertheless, workers-students show difficulty to dedicate plenty of quality time to the course. Therefore, some special motivation should be put in place in order to assure they perform accordingly to the expectations.

Informatics engineering students have the opportunity of a professional activity while attending the last part of the degree. In other cases, they may choose to do an academic interim, with the aim of getting some work experience in a company. This possibility provides these students very specific technical skills, allowing them to bring new insights to the course, since no restrictions exist on the use of technologies, approaches, tools, and methods. This was the case of the Ruby technology that was introduced by suggestion of the students with very good results.

The students may bring new things to the course and to the university. The technologies used in our project, Ruby on Rails and Git, were not previously taught in the course. I insisted a lot to use them in the project. The teachers were open to accept us to try our own ideas and technologies.

(Former Students Interview 2)

For former students, it is more important that the ideas have their origin within the groups instead of being proposed by external elements (e.g., companies). Interestingly, the contribution and interest of the companies as visitors is greater when the students work their own ideas. This is a generalized idea among former students, students and teachers. In these cases, the level of commitment and the ability to surprise is much higher. Nevertheless, in some cases the projects developed within the course tend to be very focused on the personal experiences of the proponents. Again, there is a trade-off that asks 
for a good balancing and represents a challenge for students and teachers. In this way, it can be a good approach to start by stimulating students in search for problems and opportunities to which they feel motivated to contribute with robust solutions.

\section{Conclusions}

There are a few examples in the literature of courses related to informatics where entrepreneurship skills or business issues appear with more or less relevance alongside the technical requirements. These different pedagogic experiences give a good basis and departure point for establishing more ambitious approaches for the dissemination of such capabilities in students (e.g., Papayannakis et al., 2008; Silva et al. 2009). They also permit to establish comparative views and to discuss different types of strategies as well as to understand why and how they can be more or less successful. These strategies may be supported or guided by nationwide programs or they may arise from the initiative of a specific professor within the courses he/she is responsible for. Both cannot be understood if the context and the history of the programmes are not taken into account.

This article presents, analyses, and discusses two aspects related to an informatics engineering course: (1) the main ingredients that constitute it and the various modifications that have been introduced to better adapt it to the interests of both students and teachers, (2) an analysis on the relevance that the course had for students that attended it, as an educational context that allowed them to gain a set of competencies and skills that the market values and that they perceive as relevant from a professional perspective. In this sense, in addition to the students who attended the course in 2014/15, former students that are nowadays entrepreneurs in the software industry were also interviewed.

In what concerns the first aspect, this article indicates the type of projects covered, their origin, how teams are formed, the deliverables that are requested, the evaluation form, the type of mentoring, etc. The most important changes made along the seven editions of the course are focused primarily on: (1) the effort made to reduce the number of students of each team (from the initial 30 members per team to the current 8), implying a higher number of projects; (2) the preference given to projects proposed by students (avoiding external proposals or from the teaching team); (3) the obligation for students to interact with business experts throughout the project as a way to enable them to gain awareness of the constant need to adapt the business idea to find a value proposition with market potential.

Regarding the second aspect, the considerations were obtained from the opinion of the teachers, the analysis of materials related with the course, and after interviewing students and former students to collect their perceptions with respect to the course. On the basis of the data collected, we did an evaluation of the experience that the course represents for the students and we examined whether the current course empowers students to an entrepreneurial approach in the software field. The dimensions that are identified as crucial for promoting entrepreneurship capabilities among informatics engineering students are teamwork, project engagement, and contact with the market. Particularly interesting are the testimonies of the former students who have followed an entrepreneurial career, allowing us to evaluate how the course is indeed an element that positively influences this entrepreneurial attitude. Indeed, the analysis of these entrepreneurship initiatives should go beyond the course length and the limits of the university.

Thus, this case study contributes to the discussion of the importance of linking tools and design methodologies of both software engineering and business modelling. Furthermore, it presents evidence on the qualification process of students for entrepreneurship in the particular context of this type of educational projects. This case study also shows that software engineering students in general lack experience in market-oriented issues. Nevertheless, addressing business issues, within a project for developing a software product is an important ingredient in the education of engineering students. Additionally, being able to collaborate in a relatively large group is also a mandatory skill that should be stimulated. Finally, the success of such type of courses depends on how competent students are in terms of technical competencies and technology, project management skills, and market and business knowledge.

\section{References}

Anderson, J. and Markides, C. (2007) Strategic innovation at the base of the economic pyramid. MIT Sloan 
Management Review 49(1):83-88.

Blank, S. (2013) The four steps to the epiphany, 2nd edition, Pescadero, CA: K\&S Ranch.

Bogdan, R. C. and Biklen, S. K. (1994) Qualitative research for education: An introduction to theories and methods, New York, NY: Pearson.

Bonnet, H., Quist, J., Hoogwater, D., Spaans, J., and Wehrmann, C. (2006) Teaching sustainable entrepreneurship to engineering students: The case of Delft University of Technology. European Journal of Engineering Education 31(2):155-167. DOI 10.1080/03043790600566979

Bonwell, C. and Eison, J. (1991) Active learning: Creating excitement in the classroom. ASHE-ERIC Higher Education Report No. 1.

Cagiltay, N. E. (2007) Teaching software engineering by means of computer-game development: Challenges and opportunities, British Journal of Educational Technology 38(3):405-415. DOI 10.1111/j.14678535.2007.00705.x

Capretz, L.F.; Ahmed, F. (2010) Making Sense of Software Development and Personality Types, IT Professional, 12(1): 6-13. DOI: 10.1109/MITP.2010.33

Casar, J. R. (2000) Encouraging students' attitude of innovation in research universities, European Journal of Engineering Education 25(2):115-121, DOI 10.1080/030437900308508

Chesbrough, H. (2010) Business Model Innovation: Opportunities and Barriers. Long Range Planning, pp. 354 363.

Fernandes, J. M., van Hattum-Janssen, N., Ribeiro, A. N., Fonte, V., Santos, L. P., and Sousa P. (2012) An integrated approach to develop professional and technical skills for informatics engineering students, European Journal of Engineering Education 37(2):167-177. DOI 10.1080/03043797.2012.666517

Järvi, A., Taajamaa, V. and Hyrynsalmi S. (2015) Lean software startup - An experience report from an entrepreneurial software business course, Lecture Notes in Business Information Processing, volume 210, pp. 230-244, Springer. DOI 10.1007/978-3-319-19593-3_21

Johannisson, B., Landstrom, H., and Rosenberg, J. (1998) University training for entrepreneurship: An action frame of reference, European Journal of Engineering Education 23(4):477-496, DOI $10.1080 / 03043799808923526$

Markes, I. (2006) A review of literature on employability skill needs in engineering, European Journal of Engineering Education, 31(6):637-650. DOI 10.1080/03043790600911704

Mishra, A., Cagiltay, N.E., and Kilic, O. (2007) Software engineering education: Some important dimensions, European Journal of Engineering Education 32(3):349-61. DOI 10.1080/03043790701278607

Monaghan, C., Bizumic, B., Reynolds, K., Smithson, M., Johns-Boast, L., and van Rooy, D. (2015) Performance of student software development teams: The influence of personality and identifying as team members, European Journal of Engineering Education 40(1):52-67, DOI 10.1080/03043797.2014.914156

OECD (1998). Fostering entrepreneurship, Paris, France: Organisation for Economic Co-Operation and Development.

Osterwalder, A. (2004). The business model ontology: A proposition in a design science approach. Ph.D. thesis, University of Lausanne.

Osterwalder, A. and Pigneur, Y. (2010) Business model generation, Hoboken, NJ: John Wiley and Sons.

Osterwalder, A. and Pigneur, Y. (2014) Value proposition design: How to create products and services customers want, Strategyzer Series, Hoboken, NJ: John Wiley and Sons.

Papayannakis, L., Mavrotas, G., and Damigos, D. (2006) Fostering entrepreneurship in Polytechnic Universities: The Greek Experience. FINPIN Conference 'University Entrepreneurship-Incubating Processes', 11-14 June, Lathi, Finland.

Papayannakis, L., Kastelli, I., Damigos, D., and Mavrotas, G. (2008) Fostering entrepreneurship education in engineering curricula in Greece. Experience and challenges for a Technical University. European Journal of Engineering Education 33(2):199-210. DOI 10.1080/03043790801980086

Patton, M. Q. (1990) Qualitative evaluation and research methods, 2nd edition, Newbury Park, CA: Sage.

Perkins, D. (2010) Making learning whole: How seven principles of teaching can transform education, San Francisco, CA: Jossey-Bass.

Ribeiro, J. P., Alves, V., Silva, S., and Campos, J. (2014) A 3D Computed Tomography Based Tool for Orthopedic Surgery Planning, in Developments in Medical Image Processing and Computational Vision, Tavares, J. M. and Natal Jorge, R. (eds.), Lecture Notes in Computational Vision and Biomechanics, volume 19, pp. 121-137, Springer. DOI 10.1007/978-3-319-13407-9_8

Ries, E. (2011) The Lean Startup: How today's entrepreneurs use continuous innovation to create radically successful businesses, New York, NY: Crown Business.

Rosca, D. (2005) Multidisciplinary and active/collaborative approaches in teaching requirements engineering, European Journal of Engineering Education 30(1):121-128. DOI 10.1080/03043790512331313886

Saalman, E. (2009) Implementing active learning: a challenge to teachers and students in higher education. Active Learning for Engineering Education (ALE).

Silva, A., Henriques, E., and Carvalho, A. (2009) Creativity enhancement in a product development course through entrepreneurship learning and intellectual property awareness. European Journal of Engineering Education 34(1):63-75. DOI 10.1080/03043790802710201 
Stewart, D. W. and Zhao, Q. (2000) Internet marketing business models and public policy. Journal of Public Policy and Marketing 19(2):287-296.

Saunders, M., Lewis, P., Thornhill, A. (2009) Research methods for business students, $5^{\text {th }}$ edition. Pearson Education.

Szirmai, A., Naudé, W., and Goedhuys, M. (2011) Entrepreneurship, Innovation, and Economic Development, Oxford, UK: Oxford University Press.Yin, R. K. (1981) The case study crisis some answers. Administrative Science Quartely 26(1):58-65.

Yin, R. K. (2003) Case study research: Design and methods, 3rd ed., Thousand Oaks, CA: SAGE Publications. 